\title{
Original Article \\ Electronic Immunization Registry in Improving Vaccine Supply Chain Availability in Tanga City Council, Tanzania
}

Emmanuel Yohana1,2*, Shiferaw Mitiku³, P. Claver Kayumba1, Omary Swalehe4

1 EAC Regional Centre of Excellence for Vaccines, Immunization, and Health Supply Chain Management, College of Medicine and Health Sciences, University of Rwanda, Kigali, Rwanda.

${ }^{2}$ Ministry of Health Dar es Salaam, Tanzania.

${ }^{3}$ Addis Ababa University, Addis Ababa, Ethiopia.

${ }^{4}$ Mzumbe University, Dar es Salaam, Tanzania.

* Corresponding author: Emmanuel Yohana. EAC Regional Centre of Excellence for Vaccines, Immunization, and Health Supply Chain Management, College of Medicine and Health Sciences, University of Rwanda, Kigali, Rwanda. Email: eyohana79@gmail.com

\section{Abstract}

\section{Background}

Despite the advantages of the electronic registry which has been explained in other areas of health and other parts of the world, there has been no empirical research conducted with the aim of assessing the impact of the electronic immunization registry practices on the availability of immunization commodities.

\section{Objectives}

To assess the effect of electronic immunization registry practices on the availability of immunization commodities.

\section{Methods}

A cross-sectional study was carried out to health facilities providing vaccination services in Tanga City Council. A total of 27 health care workers in 27 health facilities were interviewed for availability of vaccines and their experience in using electronic immunization system in supply chain system functioning using structured questionnaires. The data from the vaccines manual ledger and electronic TImR system were also collected administered in April-June, 2019 specifically for Bacillus-Calmette Guerin (BCG), Diphtheria-Pertussis-Tetanus-Hepatis B-Haemophilus influenza type b (DPT-HepB-Hib), bi-oral polio vaccine (bOPV), Measles-Rubella and Human Papilloma Virus Vaccine (HPV). These data were analyzed by statistical software SPSS using one sample $\mathrm{T}$ test and 95\% confidence interval.

\section{Results}

The study affirmed that the mean numbers of children registered at the health facilities using electronic immunization registry was 1.5-3 times higher than the target population for the three months preceding the study given by the National Bureau of Statistics (NBS). The number of doses for the studied vaccines (DPT-HepB-Hib, measles rubella, HPV, BCG and bOPV) were found to be different in the manual and electronic TImR systems. Also, the number of doses available at the health facilities increased significantly with the number of the electronic system registered children. 


\section{Conclusion}

This study found that the adoption of Electronic immunization registry has improved the health supply chain in terms of improving the vaccines availability.

Rwanda J Med Health Sci 2021;4(2): 223-236

Keywords: Electronic, Immunization Registry, Supply chain, vaccines availability

\section{Background}

Immunization supply chain in Tanzania involves the flow of vaccines and other related immunization commodities from the national level to the service delivery point. As the vaccines and other commodities flow through the levels of services delivery, the information of the availability and quality is very important.

Tanzania introduced electronic immunization registry to capture the real time immunization data at health facility level in phased approach since 2015. The purpose of the registry was to improve immunization data quality and utilization. The initiative started in the northern region of Arusha and then rollout to the other regions such as Kilimanjaro, Tanga and Dodoma.

Comparing with manual system of recording vaccines and other commodities related information, electronic Tanzania Immunization Registry (TImR) provide real time data for the supply chain of commodities and other health related information and make it easier for rapid data collection and analysis.[1] Improvement of logistics management information system will therefore improve the availability and consumption data for immunization commodities at the health facilities.[2] Hence the new system of electronic immunization registry might improve the availability of vaccines and thereby reduce stock-out which has been shown in many countries health services delivery points.[3-4]

In Tanzania, lack of visualization of the immunization supply chain activities, complexities related to the data collection tools, defaulter tracing and incomplete data complicated vaccines availability were the major challenges of service delivery at the health facility level.[5] These challenges result into vaccines stock-out and wastages. [6] The availability of electronic data has had a positive impact in other parts of the world in improving the health supply chain and other immunization service delivery [7] as it has solved the challenges of stock-out .[8] This was proved as the use of digitalization in India has improved immunization supply chain.[9] Given the importance of the health sector, these innovation and data for immunization supply chain are hence found to be the priority of the Global Vaccines Alliance for the years from 2016-2020.[10]

Many empirical evidences have shown that the electronic system and other technologies could improve immunization program as it has positive effect on data collection, analysis and application [11] and hence the coverage of children under the age of one year [7] can be higher. As Tanzania struggles to 
reach the last child in immunization there is a need to improve data collection tools and supply chain management information system so that the vaccines and other commodities are available in the immunization area at the time of immunization. The electronic tools at the health facilities level such as Tanzania Immunization Registry are hence important to ensure registration of all the target population and hence proper estimation for immunization commodities.[12] Electronic registry system will also enable the health information and supply chain data to be captured and easily stored and retrieved any time needed.[13]

Before the introduction of the electronic registry poor data in the health facilities has caused poor quantification and forecasting of vaccines and related commodities in third of the countries affecting the availability in the health facilities.[14] Other studies have shown problems and challenges of adopting the technologies in ensuring the health services, which can result to poor accessibility and equity.[15] With the introduction of TImR and Vaccines Information Management Information System in Tanzania (VIMS) and Tanga been one of the first region for roll-out, the immunization supply chain might be improved due to the proper estimation of the target in each respective level. However, it is unclear to what extent the TImR impact the health supply chain management in terms of vaccines availability and improvement of manual recording tools.
Alberto E. Tozz et al noted that only few countries have been successful in using electronic data to improve immunization services [11] and this study will help to understand the impact and challenge of the electronic immunization registry systems in vaccine supply availability in Tanga. Hence, this study is intended to provide evidence on role of electronic immunization registry practices on the availability of immunization commodities and identify factors affecting the effective utilization of Electronic immunization registry to improving vaccine supply chain availability at health facilities in Tanga City Council, Tanzania. More specifically, this study intended to a) assess stock levels of selected childhood vaccines such as BCG, bOPV, DPTHepB-Hib, MR and HPV after the introduction of TImR; (b) compare manual recording system and TImR data with physical counts in term of record keeping; (c) compare the number of target population given by National Bureau of Statistics with TImR recorded child registration; and (d) identify the major challenges of using TImR in recording immunization data in the health facilities

The use of these information system and electronic registry will save the cost of managing immunization system and other health systems.[16]

\section{Methods}

\section{Study design, sites, and population}

The cross-sectional descriptive research design was adopted to conduct the study among health facilities providing 
immunization services in Tanga City Council in June, 2019. The council is situated in the northern coastal area of Tanzania. The respondents were health care workers providing immunization services in the facilities. All the respondents were working with immunization services at the time of the interview. Each health facility sampled had one health care providing immunization services at the reproductive and child health clinic.

\section{Sample size and sampling strategy}

\section{Quantitative}

The sample size was 27 out of 28 available health facilities giving immunization services and the respondents were the health workers providing immunization. In each health facility one health worker providing immunization service was interviewed. This sample size was calculated using Yamane's formula $n=N /\left(1+N^{2}\right)$ Where; $\mathrm{n}=$ Sample size, $\mathrm{N}=$ Population size, $\mathrm{e}=$ margin of error

\section{Qualitative}

Interviews were also conducted among the district and regional immunization officers where the information on the challenges and other issues related to the use of electronic system was extracted.

\section{Data collection instrument and procedure}

As there was no existing validated questionnaire, structured questionnaires designed by the researcher were used to collect primary data from health care workers in the immunizing facilities in order to assess the effects of using the TImR. The questionnaires were pre-tested at the regional and district hospital before the actual data collection is took place. The questionnaire included information on the frequency of the use of the electronic system, number of children registered, vaccines doses available and recorded in electronic and manual ledgers, perception on the improved vaccines availability and challenges of using the system.

\section{Data collection procedure}

\section{Quantitative data collection}

Quantitative data collection was done by researcher using structured questionnaires which were administered to health care workers providing vaccination services at the time of the visit. The detailed explanation about the study was given to participants and any question regarding the study was addressed before they gave their consent to participate in the research. After the participants have agreed to participate in the study they were interviewed by the researcher who filled the questionnaires.

\section{Qualitative data collection}

Additionally, qualitative data on the challenges of using TImR system and how it interact with other information systems was obtained from the district and regional immunization officers.

Review of health facilities documents 
Data from immunization/health commodities ledger and electronic register were also used to obtain comparative data for vaccines availability for the study.

\section{Data analysis}

Collected data were checked for its consistency and analyzed using IBM SPSS Statistcs 20 computer software. Descriptive and inferential statistics mainly one sample T-test and correlation analysis were used. Additionally, content analysis was conducted for the qualitative data collected.

\section{Ethical consideration}

Research ethical permission was obtained from Mzumbe University number $\mathrm{MU} / \mathrm{DCC} / \mathrm{OF} / \mathrm{S} .2 / 4 / 5$. The respondents gave verbal consent for their participation to the study after the researchers gave the information about the study.

\section{Results}

All the health facilities (27) providing immunization registry services participated in this study were using the electronic and manual data management system for supply chain and $70 \%$ of them were dispensaries, $26 \%$ were health centers and $4 \%$ were hospitals.

For the studied vaccines Viz., BCG, bOPV, DPT-HepB-Hib, Measles-Rubella and HPV the mean doses of the available vaccines was higher in the TImR system compared to the actual physically available data and in manual ledger. Table 1 below show the number of doses in the electronic TImR ledger which is 3 times higher than the physically available at the facility. The manual ledger was also different from physical counts.

Table 1. bOPV and BCG vaccines data in different forms of records compared to physical counts (survey, 2018)

\begin{tabular}{|c|c|c|c|c|c|c|c|c|}
\hline \multirow{4}{*}{\multicolumn{2}{|c|}{$\begin{array}{l}\text { Data in different } \\
\text { forms of records } \\
\text { and physical } \\
\text { counts }\end{array}$}} & mean & \multicolumn{6}{|c|}{ Test Value $=0$} \\
\hline & & \multirow{3}{*}{ mean } & \multirow[t]{3}{*}{$\mathbf{T}$} & \multirow{3}{*}{ Df } & \multirow{3}{*}{$\begin{array}{l}\text { Signific } \\
\text { ant (2- } \\
\text { tailed) } \\
\text { p-value }\end{array}$} & \multirow{3}{*}{$\begin{array}{l}\text { Mean } \\
\text { Differ } \\
\text { ence }\end{array}$} & \multicolumn{2}{|c|}{ 95\% Confidence } \\
\hline & & & & & & & \multicolumn{2}{|c|}{$\begin{array}{l}\text { Interval of the } \\
\text { Difference }\end{array}$} \\
\hline & & & & & & & Lower & Upper \\
\hline \multirow{2}{*}{$\begin{array}{l}\text { bOPV } \\
\text { ledger) }\end{array}$} & \multirow[t]{2}{*}{ (manual } & 117.2 & 5.08 & \multirow[t]{2}{*}{21} & \multirow[t]{2}{*}{.000049} & 117.2 & \multirow[t]{2}{*}{69.30} & \multirow[t]{2}{*}{165.24} \\
\hline & & 7 & 4 & & & 7 & & \\
\hline \multirow{2}{*}{$\begin{array}{l}\text { bOPV } \\
\text { record) }\end{array}$} & \multirow[t]{2}{*}{ (TImR } & 243.0 & 4.41 & \multirow[t]{2}{*}{26} & \multirow[t]{2}{*}{.000157} & 243.0 & \multirow[t]{2}{*}{129.91} & \multirow[t]{2}{*}{356.09} \\
\hline & & 0 & 7 & & & 0 & & \\
\hline \multirow{2}{*}{$\begin{array}{l}\text { bOPV } \\
\text { count) }\end{array}$} & \multirow{2}{*}{ (Physical } & 83.33 & 5.87 & \multirow[t]{2}{*}{23} & \multirow[t]{2}{*}{.000005} & 83.33 & \multirow[t]{2}{*}{54.01} & \multirow[t]{2}{*}{112.66} \\
\hline & & & 8 & & & & & \\
\hline
\end{tabular}




\begin{tabular}{|c|c|c|c|c|c|c|c|c|}
\hline $\begin{array}{l}\text { BCG } \\
\text { ledger) }\end{array}$ & (manual & $\begin{array}{l}129.0 \\
9\end{array}$ & $\begin{array}{l}5.37 \\
0\end{array}$ & 21 & .000025 & $\begin{array}{l}129.0 \\
9\end{array}$ & 79.10 & 179.08 \\
\hline $\begin{array}{l}\mathrm{BCG} \\
\text { record) }\end{array}$ & (TImR & $\begin{array}{l}306.8 \\
9\end{array}$ & $\begin{array}{l}5.54 \\
9\end{array}$ & 26 & .000008 & $\begin{array}{l}306.8 \\
9\end{array}$ & 193.22 & 420.56 \\
\hline $\begin{array}{l}\text { BCG } \\
\text { count) }\end{array}$ & (Physical & $\begin{array}{l}102.5 \\
0\end{array}$ & $\begin{array}{l}6.68 \\
3 \\
\end{array}$ & 23 & .000001 & $\begin{array}{l}102.5 \\
0\end{array}$ & 70.77 & 134.23 \\
\hline
\end{tabular}

It was noted that there were differences in the two systems as compared to the actual available vaccines in the facilities. The electronic TImR data was higher for BCG and measles rubella vaccines in the facilities.

The study also showed that there were correlation between amount of vaccines available at the health facilities and target population. As the number of the target population increased so was the doses of the vaccines available at the facility. The correlation was 0.944 and significant at $95 \%$ confidence interval. Table 2 shows the correlation between the number of doses of DPT-HepB-Hib and the target population of the visited facilities.

Table 2. Correlation between the number of doses of DPT-HepB-Hib and target population

\begin{tabular}{llll}
\hline & & $\begin{array}{l}\text { Target } \\
\text { population }\end{array}$ & $\begin{array}{l}\text { DPT-HepB-Hib } \\
\text { Physical count }\end{array}$ \\
\hline Target population & $\begin{array}{l}\text { Pearson Correlation } \\
\text { Significant (1-tailed) } \mathrm{p}-\end{array}$ & 1 & $.94^{* *}$ \\
& value & .00 \\
& $\mathrm{~N}$ & 24 & 21 \\
DPT-HepB-Hib & Pearson Correlation & $.94^{* *}$ & 1 \\
Physical count & Significant (1-tailed) & .00 & \\
& $\mathrm{~N}$ & 21 & 24 \\
\hline
\end{tabular}

**. Correlation is significant at the 0.01 level (1-tailed). (Survey,2019)

Correlation between target available at the health facilities visited population and vaccines availability as shown in Figure 1 below. This means at the facilities there was enough vaccines available at the health facilities visited. The There was a correlation between target population and the amount of vaccines correlation was significant at $95 \%$ confidence interval. 


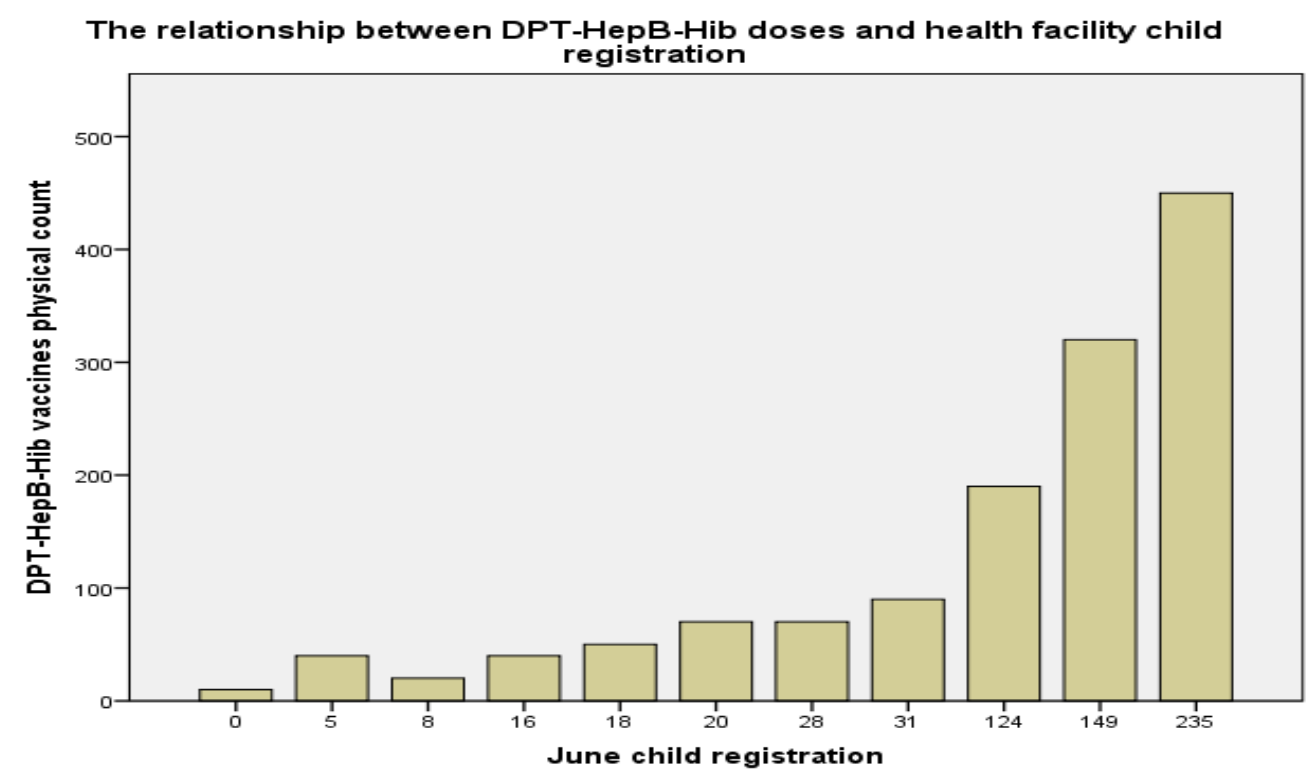

Figure 1. The relationship between DPT-HepB-Hib available doses and TImR child registration

According to Figure 1 above there was a direct relationship between electronic child registration and the number of DPT-HepB-Hib doses available at the health facilities.

The relationship between NBS given target population and TIMR child registration

The child registration done by the new electronic TImR system was higher than the National Bureau of Statistics given target. This is shown in Table 3 below

Table 3. The relationship between mean target population and TImR child registration (Survey,2019)One-Sample Test

\begin{tabular}{lccllll}
\hline & \multicolumn{6}{c}{ Test Value = 0 } \\
\cline { 2 - 7 } $\begin{array}{l}\text { NBS Target } \\
\text { population Vs and } \\
\text { child registration }\end{array}$ & T & Df $\begin{array}{l}\text { Sig. (2- } \\
\text { tailed) p- } \\
\text { value }\end{array}$ & $\begin{array}{l}\text { Mean } \\
\text { Difference }\end{array}$ & $\begin{array}{l}\text { 95\% Confidence } \\
\text { Interval of the } \\
\text { Difference } \\
\text { Lower }\end{array}$ & Upper \\
\hline $\begin{array}{l}\text { Monthly NBS Target } \\
\text { population }\end{array}$ & 4.05 & 23 & 0 & 28.96 & 14.18 & 43.74 \\
$\begin{array}{l}\text { April 2019 } \\
\text { registration }\end{array}$ & 1.61 & 10 & 0.14 & 36.55 & -13.9 & 86.99 \\
$\begin{array}{l}\text { May 2019 registration } \\
\text { June 2019 }\end{array}$ & 2.78 & 11 & 0.02 & 48.17 & 9.98 & 86.36 \\
registration & 2.6 & 11 & 0.03 & 55.33 & 8.5 & 102.17 \\
\hline
\end{tabular}


Table 3 show the mean target population for this study was less than child registered for the immunization in each three preceding month of the study (April, May and June, 2019). The registration ranged from 1.3 to 2 times higher than the National Bureau of Statistics' given target population for the health facilities. Except for April 2019 registration, the mean differences are significant for the other observed months (May and June) as the $\mathrm{p}$ value is within the acceptable region $(p=0.05)$

\section{The role of electronic immunization registry on Stock status of health commodities}

About $61 \%$ responded that the system can generate the order while 39\% did not know if the system can be used to generate vaccines order. This is important in making sure the efforts used in establish the electronic register is used in ensuring availability of vaccines and related supplies. More to this based on physical observation made to assess the availability of vaccines (stock status) at the time of visit shows that, in all the facilities (100\%) under this study had DPT-HepB-Hib vaccine at the time of the visit which was, in the middle of the month. The number of doses available at the health facilities was higher than the target quantity.

\section{Challenges of Electronic Immunization Registry (TImR system) adoption}

The reported challenges in using the electronic immunization registry were related to internet connectivity where by some areas have no or poor internet services which results to taking too long in capturing the clients or stock to the system. The tablet used were not capturing the vaccines received in the system and hence resulted to the mismatch between the quantities of vaccines available physically and those captured in the system, the generated reports were not realistic to what were expected. The other challenges were, some vaccines are not visible in the TImR system though they are rampant during working hours necessitating providing services without the use of electronic gadget and retaining the child cards for electronic data capture in some other time.

Add to this, some of the health workers affirmed that they are experiencing challenges in using some features of the system and generating the reports for their facility data use as some of them used the system to capture data only without using it generate report and use the data for the facility, a frequent system problem of the system results in returning the gadget to the district for maintenance, bundles for internet connectivity, lack of proper maintenance of the gadget, unavailability of training on minor troubleshooting of the electronic gadget or system to the health workers, lack of important reports in the TIMR system such as number of HIV exposed children in the system provide a challenge during monthly report generation and submission to the district level and some barcodes are not functional as they have worn out found 
to be the major challenges hindering effective utilization of electronic immunization registry system to improving the health supply chain in Tanga City Council.

\section{Discussions}

The health facilities in Tanga City Council had enough vaccines because TImR system can generate stock-out report which is very important in managing supply chain of the immunization commodities such as vaccines. This is because the TImR system has dashboard which can show the quantities of vaccines and syringes for immunization available at the facility. This feature can increase availability of immunization commodities at the facilities because of improved decisions and responses by the health workers. This has also been shown in other settings and countries such as Nigeria by Sarley D et al, 2017 [17] who showed that implementing electronic system would ensure vaccines availability. Also one review has clarified that poor vaccines management at the services delivery level results into stock out of vaccines.[18]

The results of the present study showed that there was correlation between NBS given target population and the available doses of vaccines at the health facilities. The number of doses of vaccines increased with increase in target population at the facility. Also the correlation was positive with the number of registered children using the electronic system. This improved availability of vaccines at their health facilities is due to automatic calculation of the vaccines needed at any one time by the electronic system. The availability of vaccine would hence improve immunity to the community as any time the child visit the facility would be vaccinated. The results of this study is consistent with other empreical studies conducted with different sister system for essential medicines called eLMIS which has been shown to improve the supply chain parameters after one year of implementation.[19, 20]

The number of doses for different vaccines in TImR and immunization's manual ledger were different but comparing to those available physically the immunization ledger was very close to the physically available data. For example, for the bOPV vaccines the electronic immunization registry had a record which shows that value is about four times the number of vaccines present in the facilities. For the ledger the records show that about 1.5 times higher compared to the physical count. This differences were noted for all vaccines available under this study and available in the facilities. This can be explained that the health workers are still using manual ledger. Also electronic immunization register has many challenges in using it at the health facility. The continuing use of the manual ledger despite been the government's policy impede the full implementation of the electronic system as the health workers at the facilities feel that using the two systems duplicates their works. Also the difference in number of doses in the two systems can 
be explained by the challenges related to internet connectivity. This affect the real time data visibility at the higher level and hence the decisions in the supply chain as has been studied noted by other authors such as Thiyagarajan A and Bhattacharya DK.[21]

Through this study the number of registered children electronically were higher than the target population given to the facilities for immunization. The differences were up to 2 times as shown in Table 3. This increased number of children to be vaccinated compared to the target number given may be due to challenges of distribution of the target population in the health facilities which usually result some facilities to record more than $100 \%$ of their performances while others recording poor performance. Also as service users are free to get services everywhere they want with electronic TImR system information can easily be captured and visualized. These issues were also noted by Aporphia Namageyo-Funa, Anita Samuel et al and showed that they are all prevalent in Africa .[12] The increase in the number of target population as compared to the given target can also result in the decrease in number of vaccines available at any time at the facility but the improved visibility and availability of dashboard for vaccines availability increase the action of the supervisors. These uncertain target population and inadequate supply chain management were also reported by other authors in Tanzania and Zambia such as Seymour D, Werner L, and Mwansa FD et al and was the reason behind the introduction of TImR in the country [22] which was expected to reduce the number of stock-out among other challenges.

Despite the use of TImR electronic system in managing vaccines and its advantages in improving the availability of vaccines in health facilities in Tanga City Council there have been many challenges related to the new system such as internet connectivity. The internet connectivity was mentioned by most of the health workers involved in immunization as one of the challenge affecting the new system. Other challenges which were noted were too many papers for manual data entry despite the new electronic system, human resources constraints and breakdown of the gadget for data collection tool at the facilities as has been reported in countries.[23] These challenges have also been noted in other developing countries which are using EIR and sometimes results into underreporting as reported by Dolan SB, Carnahan E and Shearer JC et al [24] and Trumbo SP, Contreras M and Garcia A in 2018.[25] Addressing the challenges would ensure electronic immunization registration is implemented for the exchange of health and supply chain information in and outside the geographical area and hence improving ordering and inventory management.[26] The high number of clients with internet challenges was noted to cause facilities health care workers to collect the child health cards for updating the records after the clinic session affecting the quality of data. This 
result was also consistent with the one study conducted in Ethiopia for ART clinic [27] which showed the paper and electronic tools are used parallel. The use of simple manual backup system in all health facilities and additional electronic gadget in facilities with high number of target population and staff will ensure data collection and visibility will continue even when there is a problem with the gadget.

\section{Conclusions}

The stock of vaccines available at the facilities in Tanga City Council was enough to provide immunization services in their respective facilities because of the positive correlation with the target population and the electronic child registration.

The mean doses for the vaccines under study were different in the TImR and manual ledger. However, the manual ledger records were closer to the physical available data than the electronic records. For example, for BCG the mean dose available at the health facilities was 102.5 while, the manual ledger was 129 and TImR 306.9. This difference is due to the challenges of managing the TImR system at the facility due to among other internet connectivity problems. The number of electronic registered children at the facilities was fewer than NBS targets given. This electronic child registration is hence important in ensuring enough vaccines are distributed to the facilities when the NBS target is unrealistic. Most health workers in the facilities providing immunization services were very happy with the new TImR system in use despite of the challenges they experienced in the use of the system. Some of the challenges were related to the internet connectivity, human resources, preventive maintenance of the gadget for data collection and support services.

\section{Competing interests}

There no conflict of interests for all authors, being financial or nonfinancial.

\section{Acknowledgement}

The authors of this paper gratefully acknowledge the funding of the Masters of Health Supply Chain Management by the German Federal Ministry for Economic Cooperation and Development (BMZ) through KfW Development Bank and the East African Community Regional Center of Excellence for Vaccines, Immunization, and Health Supply Chain Management. In addition, this research would not have been possible without the assistance of the College of Medicine and Health Sciences, University of Rwanda.

This article is published open access under the Creative Commons Attribution-NonCommercial NoDerivatives (CC BYNC-ND4.0). People can copy and redistribute the article only for noncommercial purposes and as long as they give appropriate credit to the authors. They cannot distribute any modified material obtained by remixing, transforming or building upon this article.

See https://creativecommons.org/licenses/by-ncnd $/ 4.0 /$ 


\section{References}

1. Heidebrecht CL, Kwong JC, Finkelstein M, Quan SD, Pereira JA, Quach S, et al. Electronic immunization data collection systems : application of an evaluation framework. BMC Med Inform Decis Mak. 2014;14(5).

2. Yadav P, Yadav P. Health Product Supply Chains in Developing Countries: Diagnosis of the Root Causes of Underperformance and an Agenda for Reform Health Product Supply Chains in Developing Countries: Diagnosis of the Root Causes of Underperformance and an Agenda for Refo. 2015;8604(October 2017).

3. Lydon P, Schreiber B, Gasca A, Dumolard L, Urfer D, Senouci K. Vaccine stockouts around the world: Are essential vaccines always available when needed? Vaccine [Internet]. 2020;35(17):2121-6. Available from:

http://dx.doi.org/10.1016/j.vacci ne.2016.12.071

4. Ngcobo NJ, Chb MB, Bioethics M, Law H, Kamupira MG, Chb MB, et al. The status of vaccine availability and associated factors in Tshwane government clinics. South Africa Med J. 2017;107(6):535-8.

5. PATH. Electronic immunization registries. Seattle; 2017.
6. JSI. Making Stock Data Visible How Dashboards Increase Vaccine Availability [Internet]. 2014. p. 14. Available from: https://www.jsi.com/JSInternet/ Inc/Common/_download_pub.cfm Pid $=16234 \&$ ild $=3$

7. Nguyen NT, Vu HM, Dao SD, Tran HT, Xuan T, Nguyen C. Digital immunization registry: evidence for the impact of mHealth on enhancing the immunization system and improving immunization coverage for children under one year old in Vietnam. mHealth [Internet]. 2017;3(26):1-7. Available from: http://dx.doi.org/ 10.21037/mhea lth.2017.06.03

8. Mihigo R, Okeibunor J, Anya B, Mkanda P, Zawaira F, Davis R, et al. Supplement article Case study Challenges of immunization in the African Region [Internet]. Vol. 27. 2017. Available from: http://www.panafrican-medjournal.com/content/series/27/3 /12/full

9. Skye S, Thakare N, Ramanujapuram A, Akkihal A. Assessing stability and performance of a digitally enabled supply chain: Retrospective of a pilot in Uttar Pradesh, India q. Vaccine [Internet]. 2017;35(17):2203-8. Available from:

http://dx.doi.org/10.1016/j.vacci ne.2016.11.101

10. Brooks A, Habimana D, Ma GH. 
Making the leap into the next generation : A commentary on how Gavi, the Vaccine Alliance is supporting countries ' supply chain transformations in 2016 2020 q. Vaccine [Internet]. 2020;35(17):2110-4. Available from:

http://dx.doi.org/10.1016/j.vacci ne.2016.12.072

11. Tozzi AE, Gesualdo F, Ambrosio $\mathrm{AD}$, Pandolfi E, Wilson-clark SD, Gesualdo F. Can Digital Tools Be Used for improving immunization Programs? Front Public Heal [Internet]. 2016;4(36): 1-9. Available from: https://www.ncbi.nlm.nih.gov/p $\mathrm{mc} /$ articles/PMC4782280/pdf/fp ubh-04-00036.pdf

12. Apophia Namageyo-Funa, Anita Samuel, Peter Bloland AM. Considerations for the development and implementation of electronic immunization registries in Africa. Pan Afr Med $J$ [Internet]. 2018;30(81):1-6. Available from: http://www.panafrican-medjournal.com/content/article/30/ $81 /$ full/\%0AC

13. PATH. A Realistic Review of What Works to Improve Data Use for Immunization.

14. Rao R, Schreiber B, Lee BY. Immunization supply chains : Why they matter and how they are. Vaccine [Internet]. 2017;35(17):2103-4. Available from: http://dx.doi.org/ 10.1016/j.vacci ne.2017.02.062

15. Ent MMVX Van Den, Yameogo A, Ribaira E, Hanson CM, Ratoto R, Rasolomanana S, et al. Equity and immunization supply chain in Madagascar q. Vaccine [Internet]. 2020;35(17):2148-54. Available from:

http://dx.doi.org/10.1016/j.vacci ne.2016.11.099

16. Hillestad R, Bigelow J, Bower A, Girosi F, Meili R, Scoville R, et al. Can Electronic Medical Record Systems Transform Health Care? Potential Health Benefits, Savings, And Costs. Health Aff (Millwood). 2005;24(5):1103-17.

17. Sarley D, Mahmud M, Idris J, Osunkiyesi M, Dibosa-osadolor O, Okebukola $\mathrm{P}$, et al. Transforming vaccines supply chains in Nigeria. Vaccine. 2017;35:2167-74.

18. Iwu CJ, Jaca A, Abdullahi LH, Ngcobo NJ, Wiysonge CS. Protocol for a systematic review of the effects of interventions for vaccine stock management. Syst Rev [Internet]. 2019;8(14):1-4. Available from: https://doi.org/10.1186/s13643018-0922-3

19. Mwencha M, Rosen JE, Spisak C, Watson N, Kisoka N. Upgrading Supply Chain Management Systems to Improve Availability of Medicines in Tanzania: Evaluation of Performance and Cost Effects. Glob Heal Sci Pract 
[Internet]. 2017;5(3):399-411. Available from: https://doi.org/10.9745/GHSPD-16-00395

20. Au L, Oster A, Yeh GH, Magno J, Paek HM. Utilizing an Electronic Health Record System to Improve Vaccination Coverage in Children. Appl Clin Inform [Internet]. 2010;1:221-31. Available from: http://dx.doi.org/10.4338/ACI2009-12-CR-0028

21. Arulmani Thiyagarajan, Sudip Bhattacharya DK. Role of Electronic Vaccine Intelligence Network ( eVIN ) System for Quality Improvement in Immunization Data in India. CHRISMED $J$ Heal Res. 2019;(6):128-9.

22. Seymour D, Werner L, Mwansa FD, Bulula N, Mwanyika H, Dube $\mathrm{M}$, et al. Electronic Immunization Registries in Tanzania and Zambia: Shaping a Minimum Viable Product for Scaled Solutions. Front Public Heal [Internet]. 2019;7(218). Available from:

10.3389/fpubh.2019.00218

23. Nemser B, Aung K, Mushamba M, Chirwa S, Sera D, Chikhwaza O, et al. Data-informed decisionmaking for life-saving commodities investments in Malawi: A qualitative case study. Malawi Med J. 2018;2(June):12-4.

24. Dolan SB, Carnahan E, Shearer JC, Beylerian EN, Thompson J,
Gilbert SS, et al. Redefining vaccination coverage and timeliness measures using electronic immunization registry data in low- and middle-income countries. Vaccine [Internet]. 2019;37:1859-67. Available from: https://doi.org/10.1016/j.vaccine .2019.02.017

25. Trumbo SP, Contreras M, Gabriela A, García F, Alberto F, Díaz E, et al. Improving immunization data quality in Peru and Mexico: Two case studies highlighting challenges and lessons learned. Vaccine [Internet]. 2018;36(50):7674-81. Available from:

https://doi.org/10.1016/j.vaccine .2018 .10 .083

26. Laura J. Pabst and Warren Williams. Immunization Information Systems. Public Heal Manag Pract [Internet]. 2015;21(3):225-6. Available from: https://www.ncbi.nlm.nih.gov/p $\mathrm{mc} /$ articles/PMC5873964/pdf/ni hms926682.pdf

27. Abiy R, Gashu K, Asemaw T, Mitiku M, Fekadie B. A Comparison of Electronic Medical Record Data to Paper Records in Antiretroviral Therapy Clinic in Ethiopia: What is affecting the Quality of the Data? Online $J$ Public Health Inform. 2018;10(2):1-13. 